\title{
Correction to: In memoriam: Bernardo Stolnicki
}

\author{
C. Zerbini $^{1} \cdot$ A. Orcesi Pedro ${ }^{2} \cdot$ R.M. Pereira ${ }^{3} \cdot$ M. Lazaretti-Castro ${ }^{4} \cdot$ P. Halbout ${ }^{5} \cdot$ C. Cooper $^{6,7}$
}

Published online: 26 January 2022

(c) International Osteoporosis Foundation and National Osteoporosis Foundation 2022

\section{Correction to: Osteoporos Int (2022) 33:313-313 \\ https://doi.org/10.1007/s00198-021-06235-4}

The article "In memoriam: Bernardo Stolnicki ", written by C. Zerbini, A. Orcesi Pedro, R. M. Pereira, M. LazarettiCastro, P. Halbout, C. Cooper, was originally published online on the publisher's internet portal on 17 November 2021 with Open Access under a Creative Commons Attribution Non-Commercial (CC BY-NC 4.0) .

After publication in volume 33, issue 1, page 313-313 the author(s) decided to cancel the Open Access. Therefore, the copyright of the article changed on 21 January 2022 to $($ ) International Osteoporosis Foundation and National Osteoporosis Foundation 2021 with all rights reserved.

Publisher's note Springer Nature remains neutral with regard to jurisdictional claims in published maps and institutional affiliations.

The original article can be found online at https://doi.org/10.1007/ s00198-021-06235-4.

\section{Cooper}

cc@mrc.soton.ac.uk

1 Centro Paulista de Investigação Clínica, São Paulo, Brazil

2 Osteoporosis National Specialized Committee-FEBRASGO, Regional Advisory Council-Latin America-IOF, Department of Obstetrics \& Gynecology, University of CampinasUNICAMP, Campinas, Brazil

3 Rheumatology Division, Faculdade de Medicina FMUSP, Universidade de São Paulo, São Paulo, Brazil

4 Escola Paulista de Medicina, Universidade Federal de São Paulo, São Paulo, Brazil

5 International Osteoporosis Foundation, Nyon, Switzerland

6 MRC Lifecourse Epidemiology Unit, University of Southampton, Southampton, UK

7 NIHR Musculoskeletal Biomedical Research Unit, University of Oxford, Oxford, UK 